\title{
NSU
}

Florida

Nova Southeastern University

NOVA SOUTHEASTERN

UNIVERSITY

NSUWorks

College of Psychology: Faculty Articles

College of Psychology

$1-1-1979$

\section{Driving Records of Persons Convicted of Driving under the Influence of Alcohol}

\author{
Stephen A. Maisto \\ Vanderbilt University \\ Linda C. Sobell \\ Nova Southeastern University, sobell1@nova.edu \\ Pau F. Zelhart \\ Fort Hays State University \\ Gerard J. Connors \\ Vanderbilt University \\ Terri Cooper \\ University of Tennesse
}

Follow this and additional works at: https://nsuworks.nova.edu/cps_facarticles

Part of the Psychology Commons

\section{NSUWorks Citation}

Maisto, S. A., Sobell, L. C., Zelhart, P. F., Connors, G. J., Cooper, T. (1979). Driving Records of Persons Convicted of Driving under the Influence of Alcohol. Journal of Studies on Alcohol, 40(1), 70-77.

Available at: https://nsuworks.nova.edu/cps_facarticles/67 


\title{
Driving Records of Persons Convicted of Driving under the Influence of Alcohol ${ }^{1}$
}

\author{
Stephen A. Maisto, ${ }^{2}$ Linda Carter Sobell, ${ }^{3}$ Paul F. Zelhart ${ }^{4}$ \\ Gerard J. Connors ${ }^{2}$ and Terri Cooper ${ }^{5}$
}

Summary. The average interval between convictions of driving under the influence decreases from 2 years between first and second convictions to 17, 11 and 8 months, respectively, between the second and third, the third and fourth and the fourth and fifth convictions.

B

ECAUSE alcohol is associated with a high proportion of highway accidents $(1),{ }^{6}$ major efforts have focused on preventing drinking-driving incidents (2). Generally, research in this area has attempted to determine the variables that discriminate between drinking and nondrinking drivers. Some of the identifying characteristics studied thus far include demographic variables (e.g., 3-5), drinking patterns (5) and driving records preceding drinking-driving involvement $(3,6,7)$.

Another serious problem is secondary prevention, i.e., the development of successful programs for drivers already convicted of driving under the influence (DUI). It is not that we lack treatment programs for DUI offenders (8), but that these programs have proved less than effective $(1,9)$. To compound the problem, although one of the main goals of treatment programs for drivers

${ }^{1}$ This study was funded in part by a state research contract from the Tennessee Department of Mental Health and Mental Retardation and by U.S. Public Health Service Grant No. 5 T32 AA07072-02 from the National Institute on Alcohol Abuse and Alcoholism. We thank Commissioner Joel Plummer and Mr. Thomas Smothers of the Tennessee Department of Safety for their assistance in the early phases of this project and with the data collection.

Requests for reprints should be sent to Linda C. Sobell, Alcohol Programs, Dede Wallace Center, P.O. Box 40487, Nashville, Tennessee 37204.

2 Department of Psychology, Vanderbilt University, Nashville, Tennessee.

${ }^{3}$ Dede Wallace Center and Department of Psychology, Vanderbilt University.

${ }^{4}$ Fort Hays State University, Hays, Kansas.

¿University of Tennessee School of Social Work, Nashville.

Received for publication: 13 December 1977. Revision: 12 October 1978.

${ }^{8}$ Brownivg, J. J. and Wilde, G. J. S. Research in drinking and driving; a short review and annotated bibliography of research hitherto conducted. (Queen's University, Studies in Safety in Transport.) Kingston, Ontario; 1975. [Mimeographed.] 
convicted of DUr is to reduce recidivism rates, which can be measured objectively, evaluations of Dur treatment programs have been flawed by poor methodology and inadequate measures of outcome $(10,11)$.

The present report describes a retrospective evaluation of the driving records of two samples of Tennessee drivers. The first group was selected randomly from all drivers in the State of Tennessee. The other group, a random selection of drivers receiving at least one Dur conviction during the period from 1 November 1970 through December 1971, was divided into two subgroups: single and multiple DUI offenders. It was anticipated that differences between the groups might suggest variables to be considered in the design and evaluation of primary and secondary prevention programs.

\section{METHOD}

Data Collection. Driving records of 656 drivers, randomly selected from the active files of the Tennessee Department of Safety, covered the 65-month period from 1 November 1970 through March 1976. These records contained information on driving history (e.g., convictions of various traffic violations, traffic accidents and DUI offenses) and limited demographic data.

The driving records of all persons convicted of at least one DUI offense during the 14-month period from November 1970 through December 1971 were obtained from the Tennessee Department of Safety. After these records were ordered according to driver license number, every fourth record was coded, yielding a sample of 2000 cases. Of these 2000 records, 1982 had information on at least some of the variables studied. The information collected was comparable to that collected on the sample of all Tennessee drivers.

The mean $( \pm \mathrm{sD})$ age of the sample of all Tennessee drivers was $39.14 \pm 17.00$ years compared with $42.52 \pm 12.96$ for the single and $41.84 \pm 11.42$ for the multiple offender groups. $^{7}$ In contrast to both DUI groups, which were virtually all male ( 94.8 and $98.2 \%$ of the single and multiple offenders, respectively), only $59.9 \%$ of the sample of all Tennessee drivers were men. The racial composition of the three groups was similar, $88.7 \%$ of the sample of all Tennessee drivers being Whites, and $85.8 \%$ of the single and $88.6 \%$ of the multiple offenders being Whites. Other demographic characteristics, such as socioeconomic status and urban or rural residence, could not be determined from the driving records.

\footnotetext{
${ }^{7}$ The summary statistics are based on different numbers of cases, according to the completeness of the record. Data on age were available for all drivers in the sample of all Tennessee drivers and for 1533 and 449 drivers, respectively, in the samples of single and multiple offenders. Data on sex were available for 655, 1521 and 437 drivers, and data on race for 655,1459 and 404 drivers.
} 


\section{RESULTS}

During the 65-month period, only $1.7 \%$ ( 11 of 655 valid cases) of the sample of all Tennessee drivers were convicted of 1 DuI offense and $2(0.3 \%)$ were convicted of 2 offenses; 2 of the $13 \mathrm{had}$ 1 DUI conviction associated with a traffic accident. No one in this sample was convicted of DuI following refusal to consent to a breath test.

In the sample of 1982 drivers having at least 1 conviction during the first 14 months of the study, $77.35 \%$ had 1 conviction during the entire 65-month period, $17.00 \%$ had 2, 3.94\% had 3, $0.96 \%$ had 4 , $0.55 \%$ had $5,0.15 \%$ had 6 and $0.05 \%$ had 7 . As is apparent from these data, the majority of the drivers in the Dur sample did not receive another DUI conviction during the 65-month period under study.

Of the 1533 drivers who were single offenders during the 14month period, $14.7 \%$ had a Dur conviction associated with a traffic accident during the 65-month period; and $7.2 \%$ had 1 Dur conviction and $0.4 \%$ had 2 Dur convictions following refusal to take a breath test during the 65 -month period. Of the 449 drivers who were multiple offenders during the 65 -month period, $19.6 \%$ had 1 and $2.0 \%$ had 2 Dur convictions associated with a traffic accident during the study. Of the multiple offenders, $14.7 \%$ had $1,1.8 \%$ had 2 and $0.7 \%$ had 3 Dur convictions following refusal to take a breath test during the 65-month period. Thus, more than one-fifth of the multiple offenders were convicted, on the basis of blood or breath analysis, of being legally intoxicated when involved in a traffic accident, and the multiple offenders had substantially more DuI convictions following a refusal to take a breath test than did the drivers in the other 2 groups.

The data on the sample of all Tennessee drivers suggest that the probability of receiving the first dur conviction is low. However, the conviction rates of the Dur sample suggest that the probability of receiving a second DUI conviction is relatively high: $22.65 \%$ of this sample recidivated at least once during the 65-month period, compared with 2 of the 13 (15.4\%) DuI offenders in the random sample of drivers who received a second Dur conviction. Of drivers receiving at least 2 Dur convictions during the 65-month period, 25.0\% received at least one more conviction; of those receiving at least 3 Duss, $30.4 \%$ recidivated at least once more. The remaining values are $44.1 \%, 26.7 \%$, and $25.0 \%$ for drivers receiving at least 4,5 or 6 Dur convictions. 
An important question concerning DUI recidivism is the amount of time between convictions. As the data in Table 1 show, as individuals receive additional Dur convictions, the amount of time between these convictions diminishes. In this study, the mean interval between the first and second convictions was 23.5 months, but this decreased to means of 16.8 and 10.7 months, respectively, between the second and third and the third and fourth convictions. This trend continued until the time between the fourth and fifth, the fifth and sixth, and the sixth and seventh convictions was eight months.

Table 2 presents the drivers' mean number and range of convictions for 9 different moving traffic violations. Generally, the incidence and frequency of each of these offenses were low. Although the 3 samples of drivers were comparable according to convictions for speeding and careless driving and according to suspension of a license because of a felony, they were markedly different in their convictions for other offenses. For example, drivers having multiple convictions for DUr operated a vehicle contrary to license specifications on the average 10 times more than did first offenders, and no one in the sample of all Tennessee drivers was convicted of this offense. A similar ordering of the groups of drivers occurred for average number of convictions for reckless driving, operating without a license or appropriate license, driving while the license is revoked and driving while the license is suspended. In hit-and-run convictions, both Dur subgroups were comparable, and both had appreciably more convictions than did the random sample of all Tennessee drivers.

The incidence and frequency of accidents, like those of moving traffic violations, were low across all three groups. Except for a single offender's violation of the motor vehicle law resulting in the death of another, no member of any of the groups had viola-

TABLE 1.-Percentage of 1982 DUI Offenders Reconvicted, November 1970 through March 1976, and the Number of Months between Convictions

Minimum Number of Additional Convictions
Per Cent

5.65

1.72

0.76

0.20

0.05
Mean Number (and Range) of Months between Convictions

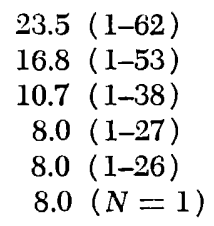


TABle 2.-Mean Number (and Range) of Convictions for Moving Traffic Violations, November 1970 through March 1976

\begin{tabular}{|c|c|c|c|c|}
\hline \multirow{2}{*}{ Offense $^{\mathrm{a}}$} & \multirow[t]{2}{*}{$\begin{array}{c}\text { All Tennessee } \\
\text { Drivers } \\
(N=656)\end{array}$} & $\begin{array}{c}\text { Single } \\
\text { DUI } \\
\text { Offenders } \\
(N=1533)\end{array}$ & \multicolumn{2}{|c|}{$\begin{array}{c}\text { Multiple } \\
\text { DUI } \\
\text { Offenders } \\
(N=449)\end{array}$} \\
\hline & & & & \\
\hline Speeding & $0.25 \quad(0-5)$ & $0.30 \quad(0-7)$ & 0.30 & $(0-8)$ \\
\hline $\begin{array}{l}\text { Careless or negligent } \\
\text { driving }\end{array}$ & $0.005(0-2)$ & $0.002(0-1)$ & 0.007 & $(0-1)$ \\
\hline $\begin{array}{l}\text { Operating contrary to } \\
\text { specifications on license }\end{array}$ & $\mathbf{0}$ & $0.002(0-1)$ & 0.02 & $(0-1)$ \\
\hline Reckless driving & $0.04 \quad(0-5)$ & $0.12(0-3)$ & 0.25 & $(0-3)$ \\
\hline $\begin{array}{l}\text { Operating without a } \\
\text { license or appro- } \\
\text { priate license }\end{array}$ & $0.02 \quad(0-4)$ & $0.23 \quad(0-8)$ & 0.51 & $(0-9)$ \\
\hline $\begin{array}{l}\text { Leaving the scene of an } \\
\text { accident (property } \\
\text { damage) }\end{array}$ & $\mathbf{0}$ & $\mathbf{0}$ & 0.00 & $(0-1)$ \\
\hline $\begin{array}{l}\text { Hit-and-run driving } \\
\text { Driving while license }\end{array}$ & $0.002(0-1)$ & $0.016(0-2)$ & 0.013 & $(0-2)$ \\
\hline $\begin{array}{l}\text { is revoked } \\
\text { Driving while license }\end{array}$ & $0.005(0-1)$ & $0.08 \quad(0-5)$ & 0.27 & $(0-6)$ \\
\hline is suspended & $0.002(0-1)$ & $0.01 \quad(0-2)$ & 0.05 & $(0-3)$ \\
\hline
\end{tabular}

' None of the drivers' licenses were suspended because of a felony.

tions resulting in the driver's death or in damage to persons or property. However, in single and multiple Dur offenders, the mean number of nonchargeable accidents $(0.45 \pm 0.71$ and $0.49 \pm 0.82$, respectively) were twice as large as the mean $(0.24 \pm 0.59)$ of the random sample of all drivers. In accidents associated with violations resulting in property damage and violations resulting in bodily injury, the means of the random sample of drivers $(0.04$ \pm 0.21 and $0.03 \pm 0.16)$ and the single offenders $(0.06 \pm 0.25$ and $0.03 \pm 0.16$ ) were similar, but the multiple offenders' means $(0.15 \pm 0.41$ and $0.10 \pm 0.34)$ were at least 2.5 times higher than those of either of the former groups.

\section{Discussion}

These data on the incidence and frequency of DUI convictions in the general driving population and among Dur offenders are consistent with findings of previous research (8). Only a small proportion of the random sample of drivers were convicted of a DuI offense during the 65-month period studied. However, data on the sample of DUI offenders showed that the probability of receiving a second DUI increased markedly relative to the first, and that 
among multiple DUI offenders there is a high risk that they will continue to receive additional Dur convictions.

Since the middle of 1975 , there has been increased police surveillance of DUI offenders in Tennessee, but such action probably had little effect on the data described here. The official policy to crack down on DuI offenders affected drivers in the NashvilleDavidson County area more than drivers in other areas of the state, and the data used in this study were collected from all of the state's 95 counties. Moreover, the current DUI offender policy in NashvilleDavidson County was initiated near the end of the 65-month period covered in this study.

The data on traffic violations and accidents suggest that drivers convicted of at least one DUI are more likely to have accidents and to be convicted of traffic violations in the future than are drivers who do not have DUI convictions. Although limitations of the data do not allow a clear interpretation of these differences, we can suggest several hypotheses. First, most of the persons in the Dur sample were men, and men tend to drive more miles and to have poorer driving records than do women (12). It is also possible that the samples were not similar on other demographic variables (e.g., socioeconomic class) known to covary with driving records.

Some of the differences in the driving records of the samples may have resulted from the fact that Dur conviction was a criterion in the selection of samples. Violations such as driving without a valid license and driving on a restricted license could vary with DUI convictions merely because people convicted of DuI usually have their license suspended or revoked, and thus have greater opportunity to be convicted of these types of violations. However, it is less apparent that a DUI conviction can account for differences in accidents and convictions of hit-and-run driving. Clearly, the differences in driving profiles are important and should be studied further.

The data have implications for implementation and evaluation of prevention programs for DUI offenders. Clark (6) has found that persons selected on the basis of alcohol-related offenses show more deviant driving records preceding the incident for which they were selected than do persons in the general population. Since the present study covered a considerable period of time following a DUI conviction, our findings suggest that people convicted of DUI may be poor drivers following as well as preceding their conviction. In view of Clark's findings (6) and ours, it would be worthwhile to study the usefulness of identifying potential DuI of- 
fenders on the basis of their records of traffic violations and accidents. These data also suggest that it may be useful to aim secondary prevention programs at first offenders as well as recidivist drunken drivers, and to include in secondary prevention programs for DUI offenders a course on responsible driving.

Unfortunately, the effects of primary and secondary interventions could not be evaluated in the present study because of limitations of the data. During the period covered by these data, driving records did not document attendance in alcohol education programs. However, the finding that the mean interval between first and second Dur convictions was about 23 months indicates that if DuI recidivism is used as a criterion in the evaluation of a treatment program for drivers convicted of DuI, the appropriate follow-up period is at least 3 years. Other aspects of the driving record, such as frequency of traffic violations and accidents, may be useful follow-up measures supplementary to the rate of DUI convictions.

Although the findings of this study have a number of implications for primary and secondary prevention as well as evaluation of such intervention, several caveats are in order. First, the conclusions of this study are based on data on convictions, not arrests. When driving records must be used to assess driving behavior, arrest data are most appropriate. The data on Dur convictions described here almost certainly do not reflect all of these drivers' DUI arrests, and at the time these data were collected, the courts generally reduced the DuI charges to reckless driving if the offender (especially a first offender) agreed to participate in a treatment program. Data in Table 2 suggests that this practice was in effect during the period under study, since the mean number of convictions for reckless driving was three and six times greater for single and multiple offenders than for the sample of all drivers.

Second, although the three groups of drivers showed large differences on several of the traffic violation and accident variables, the incidence and frequency of these events were generally low, and for some types of traffic offenses and accidents there was no record of occurrence in any of the three groups. Third, the clinician and researcher must be judicious in applying the findings of the present study to individual cases. Finally, although driving records provide useful information on DuI offenders, it is important to assess attitudinal, sociocultural and psychological variables for a more balanced evaluation of DUI intervention programs $(10,13)$. 


\section{REFERENCES}

1. Whitehead, P. C. DWI programs; doing what's in or dodging what's indicated? J. Saf. Res. 7: 127-134, 1975.

2. Perrine, M. W. The Vermont driver profile; a psychometric approach to early identification of potential high risk drinking drivers. Pp. 199-223. In: IsraELstam, S. and LAmbert, S., eds. Alcohol, drugs, and traffic safety; proceedings of the 6th International Conference on Alcohol, Drugs, and Traffic Safety, Toronto, 8-13 September 1974. Toronto; Addiction Research Foundation; 1975.

3. Filkins, L. D., Clark, C. D., Rosenblatt, C. A., Carlson, W. L., Kerlin, M. W. and Manson, H. Alcohol abuse and traffic safety; a study of fatalities; DwI offenders, alcoholism, and court-related treatment approaches; final report. Prepared for U.S. National Highway Safety Bureau. (Contract Nos. FH-11-6555 and FH-11-7129.) Ann Arbor; University of Michigan Highway Safety Research Institute; 1970.

4. Carlson, W. L. Alcohol usage of the nighttime driver. J. Saf. Res. 4: 12-25, 1972.

5. Cosper, R. and Mozersky, K. Social correlates of drinking and driving. Q. J. Stud. Alcohol, Suppl. No. 4, pp. 58-117, 1968.

6. Clark, C. D. A comparison of the driving records and other characteristics of three alcohol-involved populations and random sample drivers. HIT Lab Rep. 2 (No. 10): 1-5, 1972.

7. Perrine, M. W., Waller, J. A. and Harris, L. S. Alcohol and highway safety; behavioral and medical aspects; final report. Prepared for the U.S. National Highway Traffic Safety Administration. Springfield, Va; Natl Tech. Inform. Serv.; 1971.

8. Zelhart, P. F. and Schurr, B. C. People who drive while impaired; a review of research on the drinking-driving problem. In: Estes, N. and Heinemann, E., eds. Alcoholism; physiological and psychological bases. St. Louis; Mosby; 1977.

9. ZyLMAN, R. Dwi enforcement programs; why are they not more effective? Accid. Anal. Prev. 7: 179-190, 1975.

10. Brown, P. A., Zelhart, P. F. and Schurr, B. C. Evaluating the effectiveness of reeducation programs for convicted impaired drivers. Pp. 749-753. In: Israelstam, S. and LAMbert, S., eds. Alcohol, drugs and traffic safety; proceedings of the 6th International Conference on Alcohol, Drugs, and Traffic Safety, Toronto, 8-13 September 1974. Toronto; Addiction Research Foundation; 1975.

11. Nichols, J. L. and Rers, R. J. One model for the evaluation of ASAP rehabilitation efforts. Pp. 893-926. In: Israelstam, S. and Lambert, S., eds. Alcohol, drugs and traffic safety; proceedings of the 6th International Conference on Alcohol, Drugs, and Traffic Safety, Toronto, 8-13 September 1974. Toronto; Addiction Research Foundation; 1975.

12. Israelstam, S. and Lambert, S., eds. Alcohol, drugs, and traffic safety; proceedings of the 6th International Conference on Alcohol, Drugs, and Traffic Safety, Toronto, 8-13 September 1974. Toronto; Addiction Research Foundation, 1975.

13. Browning, J. J. and Wilde, G. J. S. L'effet de l'alcool sur la perception du risque dans des situations simulées et réalistes de conduite en automobîle. Toxicomanies 10: 253-267, 1977. 